\title{
EDUCAÇÃO EMANCIPATÓRIA: A PEDAGOGIA DO DESAPRENDER A APRENDER
}

\section{EMANCIPATORY EDUCATION: THE PEDAGOGY OF UNLEARNING TO LEARN}

\author{
Artenilde Soares da Silva ${ }^{1}$ \\ Francisco Elismar da Silva Júnior ${ }^{2}$
}

\begin{abstract}
Resumo: Para dialogarmos sobre Educação Emancipatória a partir dos sentidos: políticoétnico-social apresentamos no presente texto a perspectiva de transformação das estruturas sociais, através da concepção de uma educação que ultrapasse a simples produção de seres competentes tecnicamente e disponíveis para o mercado. Tomamos como bases para o entendimento deste caminhar, a análise dos instrumentos legais, aquelas que legitimaram/legitimam o controle das manifestações destes saberes ou negaram aos afrodescendentes o acesso aos bancos escolares. Guiamo-nos pela questão: Quais práticas educativas que ensinam o desaprender dos processos de subordinação cultural e potencializam os ditos lugares de fala, de escritos, de saberes e fazeres afrorreferenciados? Nos inspiramos como orientação nas teorias e diálogos com Freire (2010), o qual nos diz que a/o sujeita/o ao fazer uso de sua condição racional, de sua autonomia permitida pela coletividade terá capacidade de transformar o seu entorno, podendo ser isso chamado de educação emancipatória. Palavras-chave: Educação; emancipação; pedagogia.
\end{abstract}

Abstract: In order to dialogue about Emancipatory Education from the senses: political-ethnicsocial, we present in this text the perspective of transformation of social structures, through the conception of an education that goes beyond the simple production of technically competent beings available for the market. We took as a basis for understanding this path, the analysis of legal instruments, those that legitimized/legitimized the control of the manifestations of this knowledge or denied Afro-descendants access to school benches. processes of cultural subordination and potentialize the so-called places of speech, writing, knowledge and Afroreferenced practices? We were inspired as guidance in theories and dialogues with Freire (2010), who tells us that the subject, when making use of their rational condition, of their autonomy allowed by the collectivity, will be able to transform their surroundings, which may be that called emancipatory education.

Keywords: Education; emancipation; pedagogy.

\section{Introdução}

imo ni agbara

(conhecimento é poder)

Na epígrafe citada aqui, propomos para início de conversa a reflexão a respeito dos conflitos que o pensar/produzir/saber gera nas relações humanas ao longo do tempo. O conhecimento como um lugar de "poder". Assim, neste trabalho, buscamos apresentar a educação não como método de adestramento ou condicionamento social, de classes, de nações ou de raças. Colocamos sobre a mesa a potente oportunidade de lançar luz às margens, evidenciando-as como centro.

\footnotetext{
${ }^{1}$ Universidade Federal do Piauí, PI, Brasil.

${ }^{2}$ Universidade Federal do Piauí, PI, Brasil.
} 
Visando uma prática educativa para a liberdade em contraponto a imposição de uma aprendizagem estruturada a partir de um formato pré-concebido por um pensar distante da realidade da/o sujeita/o colocada/o a estas margens, as quais são naturalizadas como camadas marginalizadas, fato este, que em alguns momentos faz do oprimido o seu próprio inquisidor, acuado a obedecer a uma ordem que cisma a invalidar os saberes adquiridos e enraizados nas ancestralidades afrorreferenciadas em detrimento daquelas de heranças eurocentradas.

Por assim o ser nos interrogamos: Quais práticas educativas que ensinam o desaprender dos processos de subordinação cultural e potencializam os ditos lugares de fala, de escritos, de saberes e fazeres afrorreferenciados?

Para tanto muitas questões nos inquietam neste jogo diário que cruzam saberes tradicionais e modernos, que confundem os caminhos e as fontes desses mesmos saberes, os mesmo que nos levam da inércia ao movimento, do rural ao urbano em uma encruzilhada entre o desaprender a aprender métodos enraizados e mapeados em rotas culturais que definem uma educação de subordinação de saberes, mas que também cruzam saídas libertárias a partir destas mesmas manobras aprendidas e ensinadas neste lugar fixo chamado escola e que ao mesmo tempo se fazem presentes fora dela (escola).

Podemos dizer que neste processo de análises, experimentações e construção de experiências, que nada mais são os saberes e fazeres educacionais que a sociedade brasileira elaborou ao longo da história nacional, instrumentos legais utilizados para reprimir e oprimir os elementos descendentes das culturas ditas subalternizadas. Isto simplesmente pela insistência destes, em querer/ser/representar-se como um saber/fazer, uma educação em si mesma (BRANDÃO, 2007). Adotando para si um conceito de educação fora do espaço definido como o lugar apropriado para a prática saudável, formal, adequado e legítimo de elaboração e validação do conhecimento, com fonte e autoria segura e apropriada para a garantia do progresso e da ordem da nação segundo as invenções do colonizador, esse lugar chamado escola.

Ao longo deste texto elencamos leis formuladas e reformuladas ao longo da história deste País, que legitimaram o controle das manifestações destes saberes ou negaram aos afrodescendentes o acesso aos bancos escolares, como a Constituição Federal de 22 de abril de 1824 (BRASIL, 1824) e apresentaremos também os atuais exercícios que buscam romper com as investidas anteriores que visavam sucumbir com as iniciativas do povo afro diaspórico em manter viva as suas produções e práticas educativas e a sua vontade em tomar parte dos processos oficiais de educação como, por exemplo, a Lei 11.645 de 10 de março de 2008 (BRASIL, 2008), o que consideramos um exercício de revisão dos mecanismos institucionais legislativos, embora ainda como tentativas, pois carecem de ajustes, mas mesmos assim podemos considerá-los como um ensaio que agora regem em favor dos povos antes renegados.

Seguindo este raciocínio, o qual é reforçado pelo o pensar "freireano" que nos lembra de que "os métodos da opressão não podem, contraditoriamente, servir à libertação do oprimido" (FREIRE, 1987). Ou seja, a educação para esta sociedade que se esmera a construir uma prática de progresso da humanidade cunhada na ordem, no adequar-se e no obedecer, descarta os valores das populações que residem nas comunidades periféricas. Podemos desenhar estes dizeres utilizando, perfeitamente o atual modelo de educação das escolas que frequentamos em todos os níveis, seja o fundamental, médio, superior até a pós-graduação, por mais modernas ou progressistas que pareçam ser, apresentam uma pedagogia talhada em uma cultura eurodescendente, à cópia dos processos colonizatórios.

Nos próximos passos desta escrita trataremos a educação como controle social que determina quem pode e quem não pode sentar e assentar-se nas cadeiras escolares, não como fim, mas como meios de aprofundamento das valas que separam afrodescendentes e eurodescendentes, meios estes, institucionalizados. 
Para continuação desta conversa, puxamos o assunto sobre o poder da educação no processo de libertação da pessoa a partir do tema: Educação e emancipação: prática educativa para a liberdade, afinal são os processos educativos que nos moldam humanas/os. Daremos continuidade no exercício de compreensão desse processo de moldar/construir sujeitas/os discutindo os mecanismos utilizados e eficazes que nos ensinam a subordinar e ser subordinados epistemologicamente nos aprofundando no subtema descrito como Pedagogia: a encruzilhada entre o desaprender a aprender processos de subordinações epistêmicas e por último puxará o fio sobre os instrumentos que contribuíram e /ou contribuem com estes processos de libertação ou subordinação que são as leis que tanto podem garantir ou restringir direitos definidos aqui como Instrumentos legais: as leis que subordinam saberes em um inventar de direitos.

\section{Educação e emancipação: prática educativa para liberdade}

Emancipar-se é um processo na constituição do humano podendo ser dito que é um processo histórico, já que estamos submetidos e implicados nas práticas e estruturas da vida de todas/os, através dos saberes historicamente acumulados independente de qual fonte venha tais saberes eles irão dialogar entre si nem mesmo que seja para evidenciar e/ou materializar as condições de hierarquização inventada e desenvolvida pela capacidade do humano em contrapor-se um contra o outro.

Motivada pelas Condições, estas, limitadas pelas formas de dominação das classes eurocêntricas que ainda insistem em justificar, defender e reproduzir suas teses de supremacia, reforçado por muitos sujeitos que reproduzem estas crenças e hierarquizam as relações, as quais poderiam ser compreendidas simplesmente como distribuição de funções ou tarefas sociais, como por exemplo: aquela/e que faz o crochê e aquela/e que vende o crochê, não aquela/e que produz e aquela/e que chefia o produto o que automaticamente torna-se: aquela que ganha menos e por isso é menor e aquela/e que ganha mais e por isso é maior (Explorada/o verso explorador/a).

Dessa forma poderemos compreender o processo histórico onde fazemos a nossa própria história, mas não a fazemos segundo a nossa livre vontade, mas sob as circunstâncias e confrontos aprendidos no passado, os quais nos direcionam ao entendimento dos processos educacionais, criadas a revelias de interesses de confronto ideológicos que transformam as práticas educativas em práticas políticas vigentes e normas capitalizadoras segundo os interesses de quem opera o poder.

Como afirma Saviani (2007), sobre a identificação dos elementos culturais que fazem parte desse processo histórico e precisam ser assimilados pelos indivíduos da espécie humana, dizendo que para que se tornem humanos, assumindo a sua identidade étnica é preciso que se apropriem da forma mais adequada para atingir esse objetivo, que é a transformação dos meios educativos incluindo as tecnologias e os seus sujeitos.

Como continuação deste diálogo, priorizamos a identificação desses elementos culturais, suas bases de disseminação e a propagação dos saberes.

\section{Pedagogia: a encruzilhada entre o desaprender a aprender}

Dialogar o sentido político-étnico-social da emancipação humana educativa, na perspectiva de transformação das estruturas da sociedade, adiciona pertinência na necessidade de emergir uma concepção de educação que ultrapasse o simples ensino do saber fazer, de competências. Mais do que isso, uma prática educativa que esclareça e liberte através da ampliação de mecanismos que propiciem lugar de fala, de escritas, de saberes e fazeres, de composições autorais de livre formato.

Dialogando com Freire (1987), o qual nos diz que uma vez que o sujeito faça bom uso da sua racionalidade, sem influência de crenças e preconceitos e, através de uma autonomia permitida pela 
coletividade, se tornará sujeito de transformação social. Essa etapa tem intenção de convergir para a construção de uma fundamentação possível e coerente para a educação emancipatória.

O livre acesso a fontes de informação e, porque não dizer, à produção do conhecimento por indivíduos de uma sociedade cada vez mais desigual, instrumentaliza a dinâmica do processo educativo que, pouco a pouco, assume rachaduras epistêmicas, ainda que pequenas, mas que em ação contínua superará a instrumentalidade e fragmentação científica, sendo assim possível desvelar os mecanismos de dominação e alienação social. Pois ao longo da história podemos rememorar as manobras do sistema para impor um saber único em um lugar único e com acesso totalmente controlado, mas também rememoramos atos de resiliências que alteraram/alteram o resultado no final com pessoas alfabetizadas (sem acesso ao banco escolar), pessoas com acesso a terra sem condições de comprar (quilombos) e várias outras desobstruções e mudanças de paradigmas legalizados pelo estado brasileiro.

\section{Instrumentos legais: as leis que subordinam saberes em um inventar de direitos}

Ensaiamos até aqui que a emancipação se dá através do entendimento, do conhecimento. É fundamental vislumbrar que a construção de um sujeito racional e livre é condição possível de uma sociedade democrática.

Podemos estabelecer três propriedades para o conhecimento: liberdade epistêmica, inclusão e o poder. Premissas fundamentais para o universo dicotômico sujeito-objeto. É por meio da educação que ampliamos as medidas desse universo e estreitamos as relações de dominação historicamente conservadas a título de supremacia epistemológica.

Cabe aqui, "desobediência epistêmica" citada por Mignolo (2008), em prol da educação pelo conhecimento crítico e autorreflexão crítica, partindo em defesa de um bem-estar civilizatório possível nas relações de poder numa sociedade variante em níveis sociais, de raça e gênero, cercadas por conectivos opressores de silenciamentos.

A lei de 05 de dezembro de 1824 que determinava que negros e leprosos fossem proibidos, por emenda à Constituição, de frequentar as escolas.

A lei de 1830, no art. 295 do Código Criminal do Império condenava à prisão, com trabalhos, quem não comprovasse ocupação honesta e útil (o ensaio para o que futuramente seria chamado de lei da vadiagem e teria como alvo os/as capoeiristas) (SANTOS, 2004).

Desde 1837, foi autorizado que cada província elaborasse as suas próprias leis sobre a educação pública, os chamados “Ato adicional", os quais eram basicamente a cópia uns dos outros no quesito: quem não terá acesso à educação. Como ilustração dessa verdade citamos a Lei n. 1, de 1837, e o Decreto nº 15, de 1839, sobre Instrução Primária no Rio de Janeiro.

A lei de 11 de outubro de 1890 consolida a repressão das manifestações culturais afrodescendente no art. 402 da Lei de Vadiagem a qual tipifica a prática pública da capoeira como crime.

A lei de 03 de outubro de 1940, é reforçado no art. 59 da Lei de Contravenções Penais a qual impõe pena de 15 dias a 3 meses para quem for considerado vadio, acrescentado aqui os bêbados e os mendigos, além daqueles que não conseguissem comprovar trabalho fixo e/ou com ganho suficiente para a sustentação de um indivíduo (SERAFIM; AZEREDO. 2011).

A lei de 18 de setembro de 1945 no Art. $2^{\circ}$ do Dec. 7967, com a intenção de disciplinar a política brasileira de imigração, dispõe: “Atender-se-á, na admissão dos imigrantes, à necessidade de preservar e desenvolver, na composição étnica da população, as características mais convenientes da sua ascendência europeia, assim como a defesa do trabalhador nacional".

Quadro 1- Instrumentos legais de velhas práticas - Fonte: Os autores, 2020 
Estas colocações comprovam que as leis cumprem um propósito de higienização social segundo interesses de uma classe que legisla para si própria, podendo delegar direitos e impor deveres diferenciados para grupos sociais com base em critérios discriminatórios evidentes. Traçando um comportamento cultural com foco na educação, espaço de solidificação destes decretos. Podemos também ilustrar aqui as recentes interferências que as ações ditas afirmativas têm encorpado na busca de uma desconstrução do aprender que negativa a história, a cultura e o "corpo" de um povo.

No entanto, leis estão sendo elaboradas e aprovadas na tentativa de positivar os fazeres e saberes das populações afrodescendentes, antes já estigmatizados legislativamente. Assim podemos perceber através da citação abaixo que só a partir de 1951 é que se inicia um exercício de ruptura com estas práticas institucionais.

\begin{tabular}{|c|}
\hline \\
\hline dezembro de 1985 Governo do Rio emite \\
\hline $\begin{array}{l}\text { A lei de } 13 \text { de maio de } 1997 \text { Altera os arts. } 1^{\circ} \text { e } 20^{\circ} \text { da Lei } n^{\circ} 7.716 \text {, de } 5 \text { de janeiro de } 1989 \text {, que define os crimes } \\
\text { resultantes de preconceito de raça ou de cor, e acrescenta um parágrafo ao art. } 140 \text { do Decreto-lei } n^{\circ} 2.848 \text {, de } 7 \\
\text { de dezembro de } 1940 \text { que trata sobre esse tema. }\end{array}$ \\
\hline $\begin{array}{l}\text { A lei de } 13 \text { de maio de } 2002 \text {. O decreto } 4229 \text { institui o PNDH, que legaliza as políticas gerais de proteção aos } \\
\text { direitos humanos e legitima a discriminação positiva. }\end{array}$ \\
\hline $\begin{array}{l}\text { A lei de } 09 \text { de janeiro de } 2003 \text { A lei } 10.639 \text { incluiu no currículo oficial da Rede de Ensino a obrigatoriedade da } \\
\text { temática "História e Cultura Afro-Brasileira". }\end{array}$ \\
\hline $\begin{array}{l}\text { A lei de } 10 \text { de março de } 2008 \text { A lei } 11.645 \text { acrescenta temas de valorização da população e da cultura indígena à } \\
\text { lei } 10.649 / 03 \text { que trata da obrigatoriedade de inclusão no currículo oficial da Rede de Ensino da temática "História } \\
\text { e Cultura Afro-Brasileira". }\end{array}$ \\
\hline $\begin{array}{l}\text { A lei de } N^{\circ} 12.288 \text {, de } 20 \text { de julho de 2010, Estatuto da igualdade racial nos itens e páginas: Capítulo II - Do } \\
\text { Direito à Educação, à Cultura, ao Esporte e ao Lazer - Seção I - Disposições Gerais, pág. 16; Seção II - Da } \\
\text { Educação, pág. 16; Seção III - Da Cultura, pág. } 17 .\end{array}$ \\
\hline $\begin{array}{l}\text { A lei de } 02 \text { de maio de } 2016, \mathrm{~N}^{\circ} 13.278 / 2016 \text {, que inclui as artes visuais, a dança, a música e o teatro nos currículos dos } \\
\text { diversos níveis da educação básica. A nova lei altera a Lei de Diretrizes e Bases da Educação Nacional (LDB - Lei } \\
\text { 9.394/1996) estabelecendo prazo de cinco anos para que os sistemas de ensino promovam a formação de professores } \\
\text { para implantar esses componentes curriculares no ensino infantil, fundamental e médio. }\end{array}$ \\
\hline A lei de 18 de agosto de $2008, \mathrm{~N}^{\circ} 11.769$, que estabelece a obrigatoriedade do ensino $\mathrm{d}$ \\
\hline
\end{tabular}

Quadro 2- Instrumentos legais de novas práticas - Fonte: Os autores, 2020.

É importante dizer que aqui aparecem as leis que discutem sobre a arte dentro da escola, porque compreendemos que estes temas são essenciais em qualquer cultura e se esses instrumentos legais forem efetivados pode ser uma fenda para que os elementos de origens afrodescendentes sejam também incorporados e legitimados neste espaço.

\section{Considerações finais}

Concluímos que as lutas sociais que reverberam positivando nos saberes, fazeres e estéticas afrorreferenciadas podem ser entendidos como práticas educativas emancipatórias, no sentido de forçar mudanças na legislação educacional arranhando as velhas práticas através dos cruzamentos entre arte, cultura e luta. Neste sentido o desaprender a aprender se torna ferramenta de reflexão potente contra o colonialismo, alterando o status quo imposto por uma educação engessada e dualista. 
No entanto, é necessário estar alerta para as armadilhas que este sistema colonizador mantém como energia vital e renovável, apresentando as mesmas estratégias de encantamentos como a elaboração de leis que serão efetivadas parcialmente, com interpretações confusas e fáceis de serem manobradas e desvirtuadas.

Acreditamos que o poder de questionamento que as práticas culturais e artísticas possuem, as quais estão sendo consideradas aqui como manifestações políticas, podem gerar o caos ao dispersar essas energias que sustentam os mecanismos opressores, levando os fazeres educativos a pairarem no ar por alguns instantes para buscarem o equilíbrio incerto e assim fazerem ecos de desaprendizagens a partir da desconstrução de conceito de estética e de educação em um espaço que deseja isso imensamente que é a escola.

Podendo ser dito que ainda temos muito a avançar e principalmente a compreender este processo de reversão destas velhas práticas. Mas veredas são traçadas e novas pedagogias são testadas sem nos desconectarmos das grandes inovações anteriores, das quais como as/os mantenedoras/es de processos e pensamentos inventivos e herdados de nossos ancestrais. Fazendo desse momento atual, momentos de manobras e de preservação de memórias, acontecimentos, atitudes e principalmente conexão, o que possibilitará contextualizarmos o passado possibilitando um futuro, com características reais de continuidade.

Vale considerar ainda, que o afeto que liga a memória das vivências passadas com as vivências presentes e futuras fazem parte dos processos de mudanças. Para a população afrodescendente o esquecimento de fatos e narrativas que trazem dores e desencantos, parece necessário. Mas também é sabido que a oralidade tem como matéria prima a memória e que um povo que vivencia tal prática guardará para si as situações que lhe marcaram profundamente e só validará aquelas que lhe dão prazer em "reviver".

Então não contar a história dos afrodescendentes na escola tem uma intencionalidade que é o silenciamento e o impedimento do aflorar da autoestima, o que poderia ser considerado como crime. Uma prática que continua a ser legitimada como estratégia de fazer as crianças e todo o povo afrodescendente a se sentirem fruto da derrota e do fracasso e assim tornarem-se presas de uma ideologia racial suprema e que deve ser imitada, que é a cultura e a estética eurodescendente, o que dificulta a libertação do povo afrodescendente.

Assim como todos os povos em suas histórias perderam lutas e batalhas, mas também ganharam outras e podem continuar a ganhar, com a população afrodescendente não foi e nem é diferente, porque não é contado nas escolas da mesma forma que a história eurodescendente? Porque a verdade dá orgulho aos descendentes de qualquer raça. Um povo orgulhoso é um povo com autoestima e capaz de superar as limitações a si impostas.

Ficando nítido que a autoestima, como um direito, deve ser incluído nas pautas políticas de estado para que a potencialidade de produzir memória não reprima o nosso consciente e tenhamos o direito ao afeto ao nosso corpo de saberes, aos nossos antepassados por suas conquistas e capacidade de existir e inovar na invenção do bem viver.

Ensinar o segredo de vencer fronteiras e muros consolidados pelo colonizador deveria ser uma matéria curricular, pois os antepassados africanos nunca desistiram de produzir deslocamentos e que as comunidades periféricas continuam a avançar corajosamente e permanentemente contra as tentativas de silenciamentos e "não ditos".

$\mathrm{O}$ ato de contar história por quem as conhece de fato traz à memória de volta através do rememorar, trazendo à tona outras verdades, sendo viável à luz das práticas educativas de libertação que a muito tempo transitam em nosso meio por insistência do existir-existindo. Ações estas que corroem a negação da realidade, promovendo o avanço do reconhecimento legal do igual pertencimento dos afro-brasileiros, que mesmo diante da inexistência de políticas públicas eficientes, o esforço de pesquisas e das ações das/os ativistas ampliam e fortalecem a 
cultura como um fazer educativo o qual se apresenta como uma alternativa de libertação emancipatória atual e futura precisando apenas da consolidação destas atividades dentro do seio escolar de forma legitimada e constante.

\section{Referências}

BRANDÃO, C. R. O que é educação. São Paulo: Brasiliense, 2007.

BRASIL. Constituição da República Federativa do Brasil de 1824. 3. ed. Brasília: Senado Federal, Subsecretaria de Edições Técnicas, 2012. 105 p. Disponível em: https://www2.senado.leg.br/bdsf/bitstream/handle/id/137569/Constituicoes_Brasileiras_v1_1 824.pdf. Acesso em: 12 set. 2020.

BRASIL. Lei de 16 de dezembro de 1830. Presidência da República Casa Civil Subchefia para Assuntos Jurídicos. Disponível em: http://www.planalto.gov.br/ccivil_03/leis/lim/lim-16-121830.htm. Acesso em: 03 mar. 2020.

BRASIL. Decreto $n^{\circ}$ 847, de 11 de outubro de 1890 (Art. 402 - Lei da vadiagem). Câmara dos deputados. Disponível em: https://www2.camara.leg.br/legin/fed/decret/1824-1899/decreto847-11-outubro-1890-503086-publicacaooriginal-1pe.html\#: :text=Promulga\%20o\%20Codigo\%20Penal.\&text=Art.,que\%20n\%C3\%A3o\%20es tejam\%20previamente\%20estabelecidas. Acesso em: 03 mar. 2020.

BRASIL. Decreto-lei $n^{\circ}$ 7.967, de 18 de setembro de 1945. Presidência da República Casa Civil Subchefia para Assuntos Jurídicos. Disponível em: http://www.planalto.gov.br/ccivil_03/decreto-lei/1937-

1946/del7967.htm\#: :text=por\%20esta\%20lei.-,Art.,a\%20defesa\%20do\%20trabalhador\%20nacional. Acesso em: 03 mar. 2020.

BRASIL. Lei 1.390, de 3 de julho de 1951 (Lei Afonso Arinos). Presidência da República Casa Civil Subchefia para Assuntos Jurídicos. Disponível em: http://www.planalto.gov.br/ccivil_03/leis/11390.htm. Acesso em: 03 mar. 2020.

BRASIL. Lei $n^{\circ}$ 9.459, de 13 de maio de 1997. Presidência da República Casa Civil Subchefia para Assuntos Jurídicos. Disponível em: http://www.planalto.gov.br/ccivil_03/leis/19459.htm. Acesso em: 03 mar. 2020.

BRASIL. Decreto $n^{\circ} 4.229$, de 13 de maio de 2002. Presidência da República Casa Civil Subchefia para Assuntos Jurídicos. Disponível em: http://www.planalto.gov.br/ccivil_03/decreto/2002/d4229.htm\#: :text=Disp\%C3\%B5e\%20sobre \%20o\%20Programa\%20Nacional,que\%20lhe\%20confere\%20o\%20art. Acesso em: 03 mar. 2020.

BRASIL. Lei 10.639 de 09 de janeiro de 2003. Institui no currículo oficial da Rede de Ensino a obrigatoriedade da temática História e Cultura Afro-Brasileira. Diário Oficial da União. Disponível em: http://www.planalto.gov.br/ccivil_03/leis/2003/L10.639.htm. Acesso em: 16 abr. 2019. 
BRASIL. Lei 11.645 de 10 de março de 2008. Diário Oficial [da] República Federativa do Brasil. Poder Executivo. Disponível em: http://www.planalto.gov.br/ccivil_03/_ato20072010/2008/lei/111645.htm. Acesso em: 03 mar. 2020.

BRASIL. Lei $n^{o} 11.769$, de 18 de agosto de 2008. Presidência da República Casa Civil Subchefia para Assuntos Jurídicos. Disponível em: http://www.planalto.gov.br/ccivil_03/_ato20072010/2008/lei/111769.htm. Acesso em: 03 mar. 2020.

BRASIL. Lei $n^{\circ} 12.288$, de 20 de julho de 2010. Institui o Estatuto da Igualdade Racial; altera as Leis nos 7.716, de 5 de janeiro de 1989, 9.029, de 13 de abril de 1995, 7.347, de 24 de julho de 1985, e 10.778, de 24 de novembro de 2003. Presidência da República Casa Civil Subchefia para Assuntos Jurídicos. Disponível em: http://www.planalto.gov.br/ccivil_03/_ato20072010/2010/lei/112288.htm\#: :text=10\%20Esta\%20Lei\%20institui,demais\%20formas\%20de\% 20intoler\%C3\%A2ncia\%20\%C3\%A9tnica. Acesso em: 03 mar. 2020.

BRASIL. Lei $n^{\circ}$ 13.278, de 2 de maio de 2016. Presidência da República Casa Civil Subchefia para Assuntos Jurídicos. Disponível em: http://www.planalto.gov.br/ccivil_03/_ato20152018/2016/lei/113278.htm. Acesso em: 03 mar. 2020.

FREIRE, P. Pedagogia da autonomia: saberes necessários à prática educativa. 41. ed. São Paulo: Paz e Terra, 2010. Coleção Leitura.

FREIRE, P. A pedagogia do oprimido. São Paulo: Cortez, 1987.

LEI N. 1, DE 1837, E O DECRETO No 15, DE 1839. Sobre Instrução Primária no Rio de Janeiro. Disponível em: https://seer.ufrgs.br/asphe/article/viewFile/29135/pdf. Acesso em: 12 jun. 2021.

MIGNOLO, W. D. Desobediência epistêmica: a opção descolonial e o significado de identidade em política. Cadernos de Letras da UFF - Dossiê: Literatura, língua e identidade, n. 34, p. 287-324, 2008. Disponível em: https://portal.uneb.br/poscritica/wpcontent/uploads/sites/113/2019/10/Desobedi\%C3\%AAncia-epist\%C3\%AAmica-Aop\%C3\%A7\%C3\%A3o-descolonial-e-o-significado-de-identidade-em-pol\%C3\%ADtica.pdf.

Acesso em: 03 mar. 2020.

RIO DE JANEIRO. Lei $n^{\circ}$ 962, de 27 de dezembro de 1985. veda a restrição de acesso de pessoas às unidades de edifícios de qualquer natureza, mediante a discriminação do uso das entradas, elevadores e escadas dos prédios, em virtude de raça, cor ou condição social. Disponível em: http://alerjln1.alerj.rj.gov.br/CONTLEI.NSF/c8aa0900025feef6032564ec0060dfff/bd7f75f7cb851 c1d0325655400779768? OpenDocument. Acesso em: 03 mar. 2020.

SANTOS, M. S. A prisão dos ébrios, capoeiras e vagabundos no início da Era Republicana. TOPOI, v. 5, n. 8, jan./jun. 2004, p. 138-169. Disponível em: https://www.scielo.br/pdf/topoi/v5n8/2237101X-topoi-5-08-00138.pdf. Acesso em: 03 maio 2020.

SERAFIM, J. G.; AZEREDO, J. L. A (des) criminalização da cultura negra nos Códigos de 1890 e 1940. Amicus Curiae. v. 6, n. 6 (2009), 2011. Disponível em: http://periodicos.unesc.net/amicus/article/viewFile/541/533. Acesso em: 03 maio 2020. 
SAVIANI, D. Trabalho e educação: fundamentos ontológicos e históricos. Revista Brasileira de Educação, v. 12, n. 34, jan./abr. 2007. Disponível em: https://www.scielo.br/pdf/rbedu/v12n34/a12v1234.pdf. Acesso em: 12 jun. 2020.

\section{Sobre os autores}

Artenilde Soares da Silva. Mestranda em Educação pela Universidade Federal do Piauí, graduada em Licenciatura Plena em Educação artística pela Universidade Federal do Piauí (2006). Especialista em Educação, Cultura e Identidade Afrodescendente pela a Universidade Federal do Piauí (2013). Tem experiência na área de Educação, com ênfase em Educação, políticas públicas e Gênero e Afrodescendência.

E-mail: artenildesilva@yahoo.com.br.

Francisco Elismar da Silva Júnior. Integrante do Grupo de Cultura Afro Afoxá, onde atua como bailarino e coreógrafo, graduado em Educação Física, especialista em Educação Física Escolar e técnico em dança.

E-mail: elismarjuniorsil@gmail.com. 